\title{
Identification of genes for small non-coding RNAs that belong to the regulon of the two-component regulatory system $\mathrm{CiaRH}$ in Streptococcus
}

\author{
Patrick Marx', Michael Nuhn², Martá Kovács', Regine Hakenbeck', Reinhold Brückner ${ }^{1^{*}}$
}

\begin{abstract}
Background: Post-transcriptional regulation by small RNAs (sRNAs) in bacteria is now recognized as a wide-spread regulatory mechanism modulating a variety of physiological responses including virulence. In Streptococcus pneumoniae, an important human pathogen, the first sRNAs to be described were found in the regulon of the CiaRH two-component regulatory system. Five of these sRNAs were detected and designated csRNAs for ciadependent small RNAs. CiaRH pleiotropically affects $\beta$-lactam resistance, autolysis, virulence, and competence development by yet to be defined molecular mechanisms. Since CiaRH is highly conserved among streptococci, it is of interest to determine if csRNAs are also included in the CiaRH regulon in this group of organisms consisting of commensal as well as pathogenic species. Knowledge on the participation of csRNAs in CiaRH-dependent regulatory events will be the key to define the physiological role of this important control system.

Results: Genes for csRNAs were predicted in streptococcal genomes and data base entries other than $\mathrm{S}$. pneumoniae by searching for CiaR-activated promoters located in intergenic regions that are followed by a transcriptional terminator. 61 different candidate genes were obtained specifying csRNAs ranging in size from 51 to $202 \mathrm{nt}$. Comparing these genes among each other revealed 40 different csRNA types. All streptococcal genomes harbored csRNA genes, their numbers varying between two and six. To validate these predictions, S. mitis, S. oralis, and S. sanguinis were subjected to csRNA-specific northern blot analysis. In addition, a csRNA gene from $S$. thermophilus plasmid PSTO introduced into S. pneumoniae was also tested. Each of the csRNAs was detected on these blots and showed the anticipated sizes. Thus, the method applied here is able to predict csRNAs with high precision.

Conclusions: The results of this study strongly suggest that genes for small non-coding RNAs, csRNAs, are part of the regulon of the two-component regulatory system $\mathrm{CiaRH}$ in all streptococci.
\end{abstract}

\section{Background}

Post-transcriptional regulation by small RNAs (sRNAs) in bacteria is now recognized as an important regulatory mechanism modulating a wide range of physiological responses [1]. While a few bacterial sRNAs were known for quite some time, their prevalence and importance were not initially appreciated. In recent years impressive technical advances have led to the prediction and/or

\footnotetext{
* Correspondence: rbrueckn@rhrk.uni-kl.de

'Department of Microbiology, University of Kaiserslautern, D-67663

Kaiserslautern, Germany

Full list of author information is available at the end of the article
}

characterization of many novel sRNAs in various bacteria [2-4]. In Escherichia coli alone close to hundred sRNAs have been verified and new studies using deep sequencing of cDNAs (RNA-Seq) in Vibrio cholerae suggested the number of sRNAs to be several hundred [5]. Even in low-GC Gram-positive bacteria, where relatively few sRNAs had been detected [6,7], the numbers are steadily increasing [8-10].

In streptococci, information regarding sRNAs is so far restricted to two streptococcal species. Three sRNAs, fasX [11], pel [12], and rivX [13], have been detected serendipitously in Streptococcus pyogenes. A genome-wide 
study using tiling microarray and northern analysis added fourteen sRNAs in this organism [14].

In Streptococcus pneumoniae, the first sRNAs to be described in this bacterium were found in the regulon of the two-component regulatory system (TCS) CiaRH [15]. These sRNAs, designated csRNAs (ia-dependent small RNA), are transcribed from the five strongest promoters of the CiaRH regulon. They show a high degree of similarity to each other, especially in the unpaired region between the two stem-loop structures characteristic for these sRNAs. Complementarity to the ShineDalgarno (SD) [16] sequence and the start codon AUG within this unpaired region suggested that the csRNA could control translation initiation of mRNAs. More recently, nine additional sRNA have been detected in $S$. pneumoniae D39, but their regulation has not been studied in greater detail [17]. A tiling array approach using RNA from S. pneumoniae TIGR4 suggested the existence of 36 sRNAs, but none was validated by northern blot analysis [18]. While the D39 work identified only csRNA1, all five csRNAs were detected in TIGR4. Both studies produced relatively few common sRNAs indicating a need for more efficient prediction methods.

The TCS CiaRH had been identified in a screen aimed at isolating spontaneous mutants of $S$. pneumoniae resistant to cefotaxime [19]. Besides $\beta$-lactam resistance, $\mathrm{CiaRH}$ affects lytic processes, genetic competence, bacteriocin production, and virulence [20-25]. Transcriptional mapping, in vitro CiaR binding, and in vivo expression studies, identified a direct repeat sequence, TTTAAG-N5-TTTAAG, to be essential for CiaRmediated gene regulation [15]. The response regulator $\mathrm{CiaR}$ in S. pneumoniae controls 15 promoters leading to the expression of 24 genes, which are organized in 5 operons and 10 monocistronic transcriptional units.

$\mathrm{CiaRH}$ is also found in other streptococcal species and a number of studies have been performed aimed at elucidating the role of CiaRH in these organisms. In Streptococcus mutans, the system is involved in bacteriocin production, competence regulation, biofilm formation, and tolerance to environmental stresses [26-30]. Stress tolerance is also affected in CiaRH mutants of Streptococcus gordonii [31]. In Streptococcus agalactiae, intracellular survival and resistance to innate immunity defenses are diminished in CiaR-deficient strains [32]. Transcriptome studies using microarrays in S. agalactiae and S. pyogenes revealed genes regulated by the CiaRH TCS, but no overlap with the well defined CiaR regulon of $S$. pneumoniae was detected [32,33]. In S. mutans however, expression of $h t r A$, encoding a serine protease and one of the genes most strongly regulated by CiaR in S. pneumoniae, is upregulated in a ciaH mutant strain [26]. In most of these streptococci the binding site for CiaR has not been identified and the genes directly controlled by CiaR are still not known. Most recently, the CiaR binding site in $S$. mutans has been defined to be NTTAAG-N5-WTTAAG [34], which is in perfect agreement with the one determined for S. pneumoniae.

In the present communication, we set out to determine whether genes for small non-coding RNAs are always part of the CiaR regulon in streptococci. Predictions of such sRNA genes were made for those streptococcal species whose complete genome sequences were available. To validate these predictions, expression of csRNAs in Streptococcus mitis, Streptococcus oralis, Streptococcus sanguinis, and from a Streptococcus thermophilus plasmid was tested by northern blot analysis. The results of these experiments strongly suggest that genes for sRNAs are contained in all CiaR regulons of streptococci.

\section{Results}

\section{Conservation of the response regulator CiaR in streptococcal species}

The two-component regulatory system $\mathrm{CiaRH}$ is present in all streptococcal species but is apparently not found in other bacteria. Searches using the histidine kinase $\mathrm{CiaH}$ of S. pneumoniae or its extracytoplasmic sensor domain identified homologues in streptococci but not in other groups of Gram-positive bacteria such as Bacillus, Listeria, Staphylococcus, Lactobacillus, or Lactococcus [35]. The streptococcal CiaH kinase proteins share between 47 and $86 \%$ identical residues (Table 1). The cognate response regulators, however, are much more similar showing between 80 and $99 \%$ identities (Table 1). CiaR belongs to the OmpR family of wingedhelix transcription factors interacting with DNA by the recognition helix and the wings [36,37]. The recognition helix contacts particular DNA bases in the major groove and is thus determining the sequence specificity. The recognition helix of CiaR, positioned from aa 189 to 201 in the $S$. pneumoniae protein, is extremely conserved among all streptococcal CiaR response regulators (Table 1). Only valine to isoleucine replacements are detected at two positions suggesting that all $\mathrm{CiaR}$ regulators could bind to very similar DNA sequences. From these considerations we concluded that $\mathrm{CiaR}$ response regulators from streptococci should also bind to the sequence TTTAAG-N5- TTTAAG as determined for CiaR from S. pneumoniae [15].

The ciaRH genes in S. thermophilus are apparently not functional. In all $S$. thermophilus genome sequences available at the moment, ciaR is interrupted by a stop codon, while translation of full length $c i a H$ is prevented by two frame shifts. A functional CiaRH system may not be necessary in S. thermophilus due to its adaptation to the dairy niche, which appears to be mainly achieved by loss-of-function mutations [38]. 
Table 1 Similarity of CiaRH proteins of various streptococci to $S$. pneunomiae CiaRH proteins

\begin{tabular}{|c|c|c|c|}
\hline Streptococcus & $\mathrm{CiaR}^{\mathrm{a}}$ & $\mathrm{CiaH}^{\mathbf{b}}$ & $\begin{array}{l}\text { CiaR recognition } \\
\text { helix }^{c}\end{array}$ \\
\hline & & & VVEVYVSKVRKKL $^{d}$ \\
\hline S. mitis $\mathrm{B} 6$ & 99 & 86 & VVEVYVSKVRKKL \\
\hline S. oralis Uo5 & 96 & 83 & VVEVYVSKVRKKL \\
\hline S. sanguinis SK36 & 88 & 60 & VVEVYVSKIRKKL \\
\hline S. agalactiae NEM316 & 88 & 51 & VVEVYVSKVRKKL \\
\hline $\begin{array}{l}\text { S. dysgalactiae subsp. equisimilus } \\
\text { GGS_124 }\end{array}$ & 84 & 50 & VVEVYVSKIRKKL \\
\hline S. equi subsp.equi 4047 & 80 & 50 & VVEVYVSKIRKKL \\
\hline $\begin{array}{l}\text { S. equi subsp. zooepidemicus } \\
\text { MGCS10565 }\end{array}$ & 80 & 51 & VVEVYVSKIRKKL \\
\hline S. gallolyticus UCN34 & 81 & 51 & VVEVYVSKIRKKL \\
\hline S. gordonii str. Challis substr. $\mathrm{CH} 1$ & 89 & 65 & VVEVYVSKIRKKL \\
\hline S. mutans UA159 & 89 & 55 & VVEVYVSKIRKKL \\
\hline S. pyogenes MGAS315 & 84 & 51 & VVEVYISKIRKKL \\
\hline S. suis $05 \mathrm{ZYH} 33$ & 88 & 48 & VVEVYVSKIRKKL \\
\hline S. thermophilus CNRZ1066 & $86^{\mathrm{e}}$ & $47^{e}$ & VVEVYVSKI-RKKL \\
\hline \multirow[t]{2}{*}{ S. uberis 0140J } & 84 & 51 & VVEVYISKIRKKL \\
\hline & OmpR & E. coli & SIDVQISRLRRMV \\
\hline
\end{tabular}

$\mathrm{a}, \mathrm{b}$ Similarity is given in\% identical residues of S. pneumoniae R6 CiaR and CiaH, respectively.

c The CiaR recognition helix was identified according to the OmpR family comparison defining DNA binding sites [37].

${ }^{d}$ The recognition helix of S. pneumoniae R6 CiaR is shown for comparison. Residues deviating from CiaR R6 are underlined.

e ciaR is interupted by a stop codon and was artificially fused for comparison. ciaH is interrupted by two frame shifts and was artificially fused for comparison.

\section{Prediction of csRNAs in streptococci other than S. pneumoniae}

To determine whether genes for csRNAs are present in other streptococcal species BLAST searches [39] of the nucleotide collection ( $\mathrm{nr} / \mathrm{nt}$ ) data base were performed using the five pneumococcal csRNAs as query. The complete set of csRNA genes was detected in all $S$. pneumoniae genomes. Several hits were also obtained in whole genome sequences of streptococcal species other than S. pneumoniae, some of which representing most likely full-length csRNA genes, but most of the hits covered far less than $50 \%$ of the query. In addition, limited similarity to csRNAs was also detected in mobile DNA elements such as streptococcal phages or an S. thermophilus plasmid.

From these analyses it appeared likely that at least some csRNAs genes are present in streptococcal genomes, but the significance of short stretches of csRNA similarity was not clear. They could indicate more diverse csRNAs, much shorter versions or remnants of csRNAs, or they could be obtained simply by chance. To distinguish these possibilities, the presence of CiaRcontrolled promoters should be indicative. These promoters should be located in intergenic regions and be followed by transcriptional terminators. Therefore, such arrangements were searched in selected streptococcal genome sequences and sequence entries showing limited similarity to csRNA genes mentioned above. For whole genomes, one strain of each species available from the NCBI microbial genome database was chosen for analysis and two genome sequences of oral streptococci recently completed in our laboratory were also included. In total, 14 streptococcal genomes were searched revealing the presence of 58 candidates for csRNA genes (Table 2), four csRNA genes on average per streptococcal species. While for three species, S. sanguinis, S. gallolyticus, and S. gordonii, six csRNA genes were predicted, S. equi subsp. equi apparently harbors only two. Three additional csRNA genes were predicted in other GenBank entries, two in S. mitis and one on plasmid pST0 from $S$. thermophilus. [40,41] These analyses also revealed that a number of shorter hits were not significant.

For S. agalactiae, S. equi subsp. zooepidemicus, $S$. mutans, S. pyogenes, and $S$. thermophilus the genome sequences of more than one strain are available. To determine if the newly identified csRNA genes listed in Table 2 are also present in these strains, Blast searches were performed. All csRNA genes defined in one strain of a streptococcal species are detected in the other strains with one exception. The gene for csRNA14 (MGAS315) of S. pyogenes MGAS315 was only found in four out of thirteen $S$. pyogenes strains, but an identical copy is contained in S. dysgalactiae subsp. equisimilus GGS_124 (Table 2).

Comparisons of the csRNA genes among each other revealed a complex picture. Short stretches of conserved sequences are present in all genes, but overall a surprising diversity was observed. If a gene showed $80 \%$ identity to another one and had no insertions/deletions of more than three consecutive nucleotides, the two genes were considered to specify the same RNA. Applying these criteria, genes for 40 different csRNA types were predicted, which varied in size from 51 to $202 \mathrm{nt}$. Secondary structure predictions revealed 32 csRNAs exhibiting two stem-loop structures similar to the csRNAs known from $S$. pneumoniae, 16 with only the termination stem-loop, and 13 with more complex structures (Figures 1, 2, 3 and 4). In all csRNAs, sequences are present that could potentially base pair to translation initiation regions of mRNAs.

Corresponding to the great variety of csRNA sequences, the genomic locations of csRNA genes are also variable. As an example, the ruvB-uppS region of $S$. pneumoniae is shown in Figure 5 harboring csRNA genes for csRNA1, 2, and 4. In $S$. mitis $\mathrm{B} 6$, this region including csRNA genes is conserved but disrupted by insertion elements. In $S$. oralis Uo5, csRNA6 is found 
Table 2 Genes for csRNAs predicted in streptococcal species other than S. pneumoniae

\begin{tabular}{|c|c|c|c|c|}
\hline strain $^{a}$ & csRNA $^{b}$ & size $^{c}$ & begin & end \\
\hline \multirow[t]{5}{*}{ S. mitis B6 } & csRNA3(B6) & 99 & 23857 & 23955 \\
\hline & csRNA4(B6) & 96 & 1932077 & 1931982 \\
\hline & csRNA2(B6) & 97 & 1936359 & 1936263 \\
\hline & csRNA1(B6) & 94 & 1936548 & 1936455 \\
\hline & csRNA5(B6) & 146 & 1944227 & 1944082 \\
\hline \multirow[t]{5}{*}{ S. oralis Uo5 } & csRNA3(Uo5) & 100 & 21777 & 21876 \\
\hline & csRNA4(Uo5) & 93 & 1712653 & 1712561 \\
\hline & csRNA2(Uo5) & 98 & 1714371 & 1714274 \\
\hline & csRNA6(Uo5) & 200 & 1714673 & 1714474 \\
\hline & csRNA1(Uo5) & 95 & 1724567 & 1724473 \\
\hline \multirow[t]{6}{*}{ S. sanguinis SK36 } & csRNA1-1(SK36) & 91 & 65114 & 65204 \\
\hline & csRNA1-2(SK36) & 94 & 65322 & 65415 \\
\hline & csRNA7(SK36) & 85 & 67110 & 67194 \\
\hline & csRNA8(SK36) & 177 & 545784 & 545959 \\
\hline & csRNA2(SK36) & 95 & 2160890 & 2160796 \\
\hline & csRNA1-3(SK36) & 84 & 2183995 & 2183912 \\
\hline \multirow[t]{4}{*}{ S. agalactiae NEM316 } & csRNA10(NEM316) & 145 & 459709 & 459565 \\
\hline & csRNA11(NEM316) & 96 & 622777 & 622872 \\
\hline & csRNA12(NEM316) & 65 & 1755431 & 1755367 \\
\hline & csRNA13(NEM316) & 66 & 2160062 & 2160127 \\
\hline \multirow[t]{4}{*}{ S. dysgalactiae subsp. equisimilus GGS_124 } & csRNA14(GGS124) & 68 & 1514790 & 1514723 \\
\hline & csRNA15(GGS124) & 141 & 1916876 & 1917016 \\
\hline & csRNA16(GGS124) & 127 & 1975022 & 1974896 \\
\hline & csRNA17(GGS124) & 117 & 1975620 & 1975736 \\
\hline \multirow[t]{2}{*}{ S. equi subsp. equi 4047} & csRNA18(4047) & $50^{d}$ & 194835 & 194786 \\
\hline & csRNA17(4047) & 105 & 200539 & 200643 \\
\hline \multirow[t]{3}{*}{ S. equi subsp. zooepidemicus MGCS10565 } & csRNA18(MGCS10565) & 67 & 159514 & 159448 \\
\hline & csRNA19(MGCS10565) & 105 & 164153 & 164257 \\
\hline & csRNA20(MGCS10565) & 108 & 236846 & 236739 \\
\hline \multirow[t]{6}{*}{ S. gallolyticus UCN34 } & CSRNA18(UCN34) & 66 & 2864 & 2929 \\
\hline & csRNA40-1(UCN34) & 65 & 51782 & 51718 \\
\hline & csRNA9(UCN34) & 63 & 679884 & 679822 \\
\hline & csRNA38(UCN34) & 138 & 2175160 & 2175297 \\
\hline & csRNA39(UCN34) & 118 & 2189828 & 2189945 \\
\hline & csRNA40-2(UCN34) & 71 & 2266270 & 2266200 \\
\hline \multirow[t]{6}{*}{ S. gordonii str. Challis substr. $\mathrm{CH} 1$} & csRNA7(CH1) & 88 & 116691 & 116778 \\
\hline & $\operatorname{csRNA} 21(\mathrm{CH} 1)$ & 58 & 161804 & 161861 \\
\hline & csRNA2-1(CH1) & 95 & 179826 & 179920 \\
\hline & $\operatorname{csRNA} 1(\mathrm{CH} 1)$ & 87 & 1360105 & 1360019 \\
\hline & $\operatorname{csRNA} 22(\mathrm{CH} 1)$ & 202 & 1721745 & 1721593 \\
\hline & csRNA2-2(CH1) & 95 & 2038879 & 2038785 \\
\hline \multirow[t]{3}{*}{ S. mutans UA159 } & CsRNA23-1(UA159) & 79 & 44425 & 44503 \\
\hline & csRNA24(UA159) & 152 & 303857 & 303706 \\
\hline & csRNA23-2(UA159) & 81 & 1501299 & 1501219 \\
\hline
\end{tabular}




\begin{tabular}{|c|c|c|c|c|}
\hline \multirow[t]{3}{*}{ S. pyogenes MGAS315 } & CsRNA15(MGAS315) & 142 & 188268 & 188127 \\
\hline & csRNA14(MGAS315) & 68 & 1276812 & 1276745 \\
\hline & csRNA25(MGAS315) & 129 & 1784361 & 1784233 \\
\hline \multirow[t]{3}{*}{ S. suis $05 \mathrm{ZYH} 33$} & csRNA26(05ZYH33) & 172 & 52590 & 52761 \\
\hline & csRNA27(05ZYH33) & 73 & 278732 & 278804 \\
\hline & csRNA28(05ZYH33) & 51 & 352037 & 352094 \\
\hline \multirow[t]{4}{*}{ S. uberis 0140J } & csRNA29(0140J) & 84 & 46527 & 46610 \\
\hline & csRNA30(0140J) & 83 & 54985 & 55067 \\
\hline & csRNA31(0140J) & 67 & 64276 & 64210 \\
\hline & csRNA32(0140J) & 140 & 1675433 & 1675572 \\
\hline \multirow[t]{5}{*}{ S. thermophilus CNRZ1066 } & csRNA33(CNRZ1066) & 66 & 8588 & 8653 \\
\hline & csRNA34(CNRZ1066) & 85 & 42534 & 42618 \\
\hline & csRNA35(CNRZ1066) & 64 & 44784 & 44847 \\
\hline & csRNA36(CNRZ1066) & 97 & 51297 & 51393 \\
\hline & csRNA37(CNRZ1066) & 127 & 51629 & 51755 \\
\hline S. thermophilus St0 plasmid pSt0 & csRNA9(pST0) & 60 & 677 & 736 \\
\hline \multirow[t]{2}{*}{ S. mitis SF100 } & csRNA2(SF100) & 98 & 2967 & 2870 \\
\hline & csRNA6(SF100) & 200 & 3271 & 3072 \\
\hline \multicolumn{5}{|c|}{$\begin{array}{l}\text { a The sequences used for the searches have the following accession numbers: S. mitis B6 [GenBank:FN568063]; S. oralis Uo5 [GenBank:FR720602]; S. sanguinis } \\
\text { SK36 [GenBank:CP000387];S. agalactiae NEM316 [GenBank:AL732656]; S. dysgalactiae subsp.equisimilus GGS_124 [GenBank:AP010935]; S. equi subsp. equi 4047 } \\
\text { [GenBank:FM204883]; S. equi subsp. zooepidemicus MGSC10565 [GenBank:CP001129]; S. gallolyticus UCN34 [GenBank:FN597254]; S. gordonii str. Challis substr. CH1 } \\
\text { [GenBank:CP000725]; S. mutans UA159 [GenBank:AE014133]; S. pyogenes MGAS315 [GenBank:AE014074]; S. suis 05ZYH33 [GenBank:CP000407]; S. uberis 0140J } \\
\text { [GenBank:AM946015]; S. thermophilus CNRZ1066 [GenBank:CP000024]; S. thermophilus St0 plasmid pSt0 [GenBank:AJ242480]; S. mitis SF100 [GenBank:AY007504]. } \\
\text { b csRNAs are considered the same type if at least 80\% of the residues are identical with consecutive insertions/deletions of less than three nucleotides. If the } \\
\text { same type is present in one strain, the csRNAs are designated -1 and -2, respectively. } \\
\text { c Size is given in nucleotides assuming the transcriptional start seven bases downstream of the -10 region and the last U of the transcriptional terminator as the stop site } \\
\text { d csRNA gene is truncated by an insertion sequence. }\end{array}$} \\
\hline
\end{tabular}

instead of csRNA1. S. sanguinis SK36 still harbors three csRNA genes, but csRNA7 replaces csRNA4. The other species, S. gordonii CH1, S. gallolyticus UCN34, S. suis 05ZYH33, and S. uberis 0140J have only one csRNA gene at variable positions and orientations. The other streptococcal species listed in Table 1 do not harbor csRNA genes at this locus. The amazingly variable genetic context of csRNA genes is consistent with the proposed role of the csRNAs as trans-acting post-transcriptional effectors.

Detection of csRNAs in S. mitis, S. oralis, and S. sanguinis To validate the csRNA gene predictions by northern blot analysis, three streptococcal species, $S$. mitis B6, S. oralis Uo5, and S. sanguinis SK36 were chosen. The strains were grown in $\mathrm{C}$-medium to the end of exponential growth phase, conditions applied to detect csRNAs in S. pneumoniae [15]. Total RNA was extracted and separated on denaturing polyacrylamide gels. Digoxigenin labeled probes were designed to detect single csRNA types in each strain. As shown in Figure 6, all predicted csRNAs could be verified in these northern analyses. While $S$. mitis B6 (Figure 6A) and $S$. oralis Uo5 (Figure 6B) expressed five csRNAs, $S$. sanguinis produced even six of them (Figure $6 \mathrm{C}$ ). Three new csRNA types were detected, one in $S$. oralis (csRNA6) and two in S. sanguinis (csRNA7; csRNA8). The csRNAs showed the anticipated sizes indicating that the assumed starts and ends were correct. In virtually all cases more than one band was detected with one csRNA probe, which is due to termination of transcription at several positions within the poly(U) stretches, as demonstrated also for the csRNAs of $S$. pneumoniae [15]. The results of these northern analyses expand the experimentally proven csRNA types to eight. 

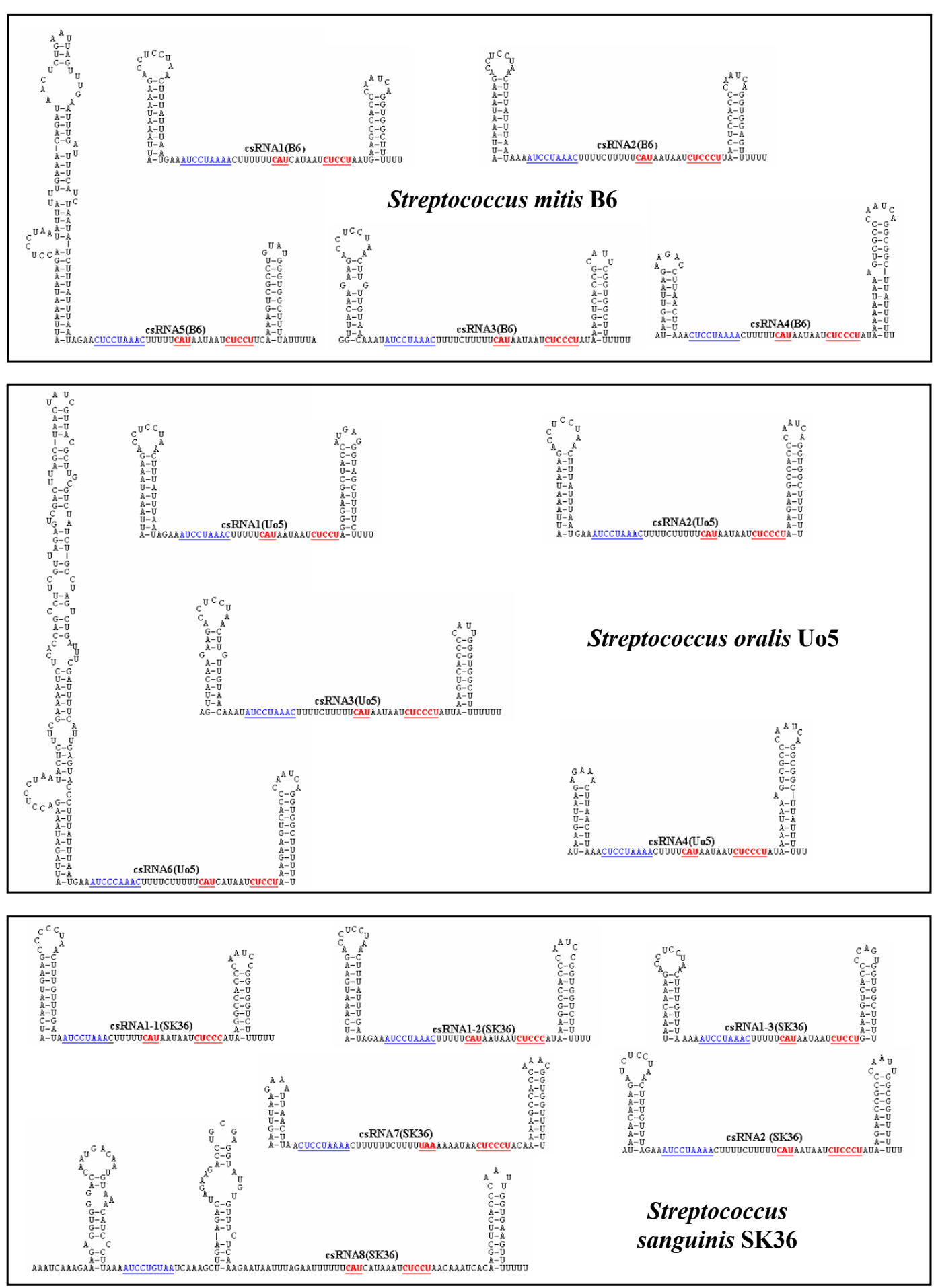

Figure 1 Secondary structures of csRNAs from S. mitis B6, S. oralis Uo5, and S. sanguinis SK36. The csRNA gene predictions from Table 2 were folded using the Mfold program [54]. Sequences complementary to Shine-Dalgarno [16] sequences or translation initiation codons are underlined and shown in red. A conserved stretch of nucleotides found in virtually all csRNAs is underlined and shown in blue. These csRNAs were verified by northern blot analysis (Figure 6). 


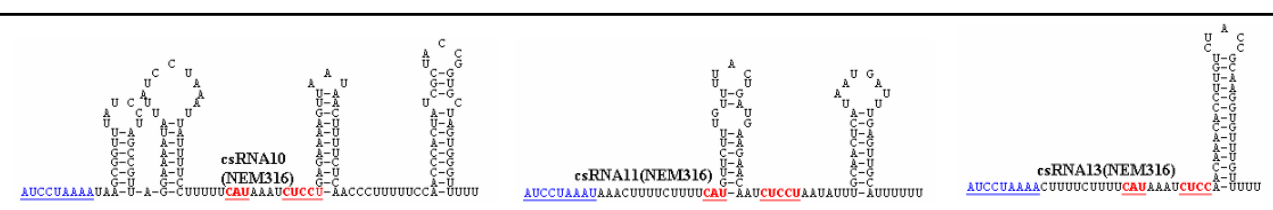

Streptococcus agalactiae

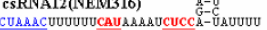

NEM316
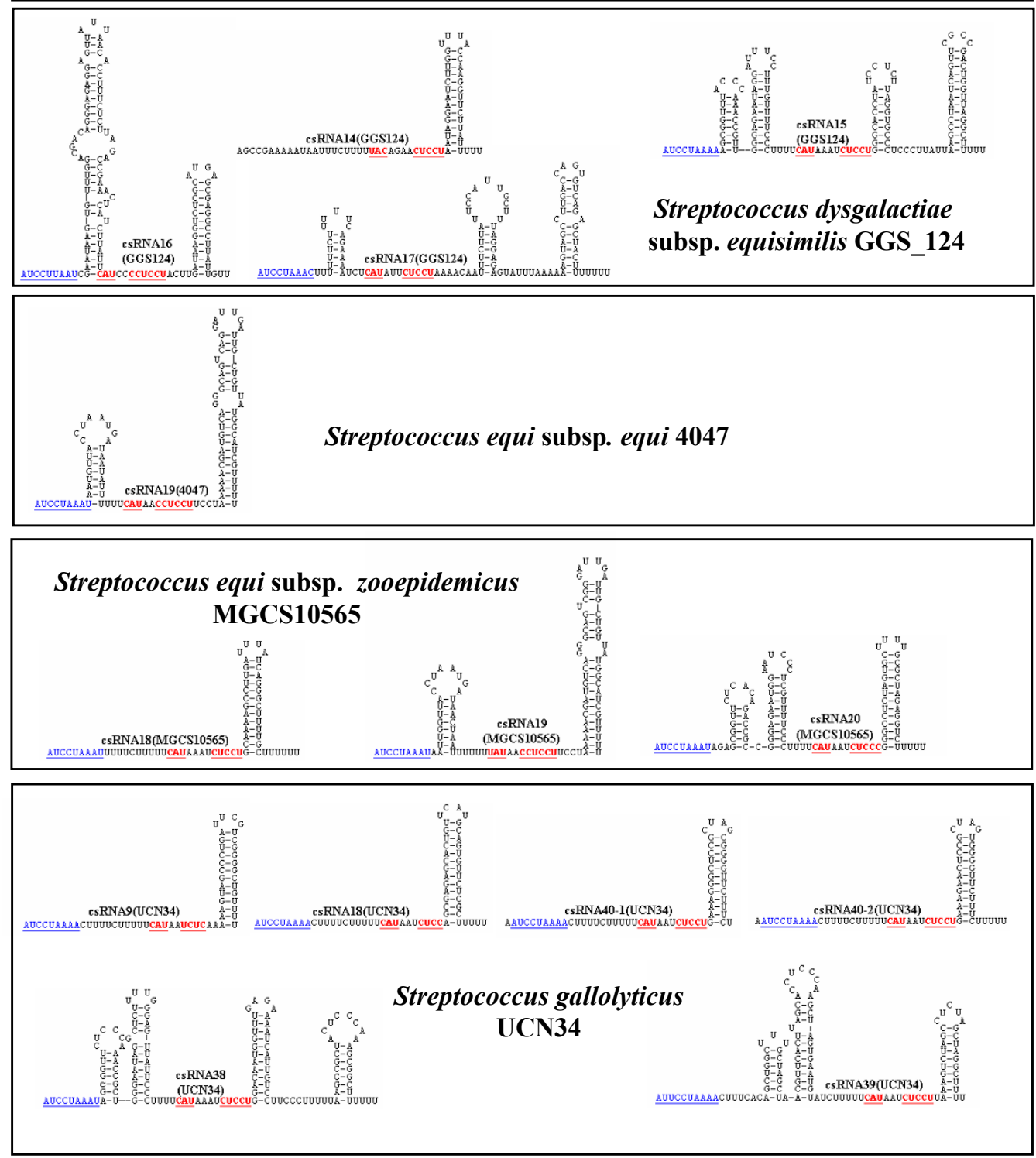

Figure 2 Secondary structures of csRNAs from S. agalactiae NEM316, S. dysgalactiae subsp. equisimilus GGS_124, S. equi subsp. equi 4047, and S. equi subsp. zooepidemicus MGCS10565, and S. gallolyticus UCN34. The csRNA gene predictions from Table 2 were folded using the Mfold program [54]. Sequences complementary to Shine-Dalgarno [16] sequences or translation initiation codons are underlined and shown in red. A conserved stretch of nucleotides found in virtually all csRNAs is underlined and shown in blue. 

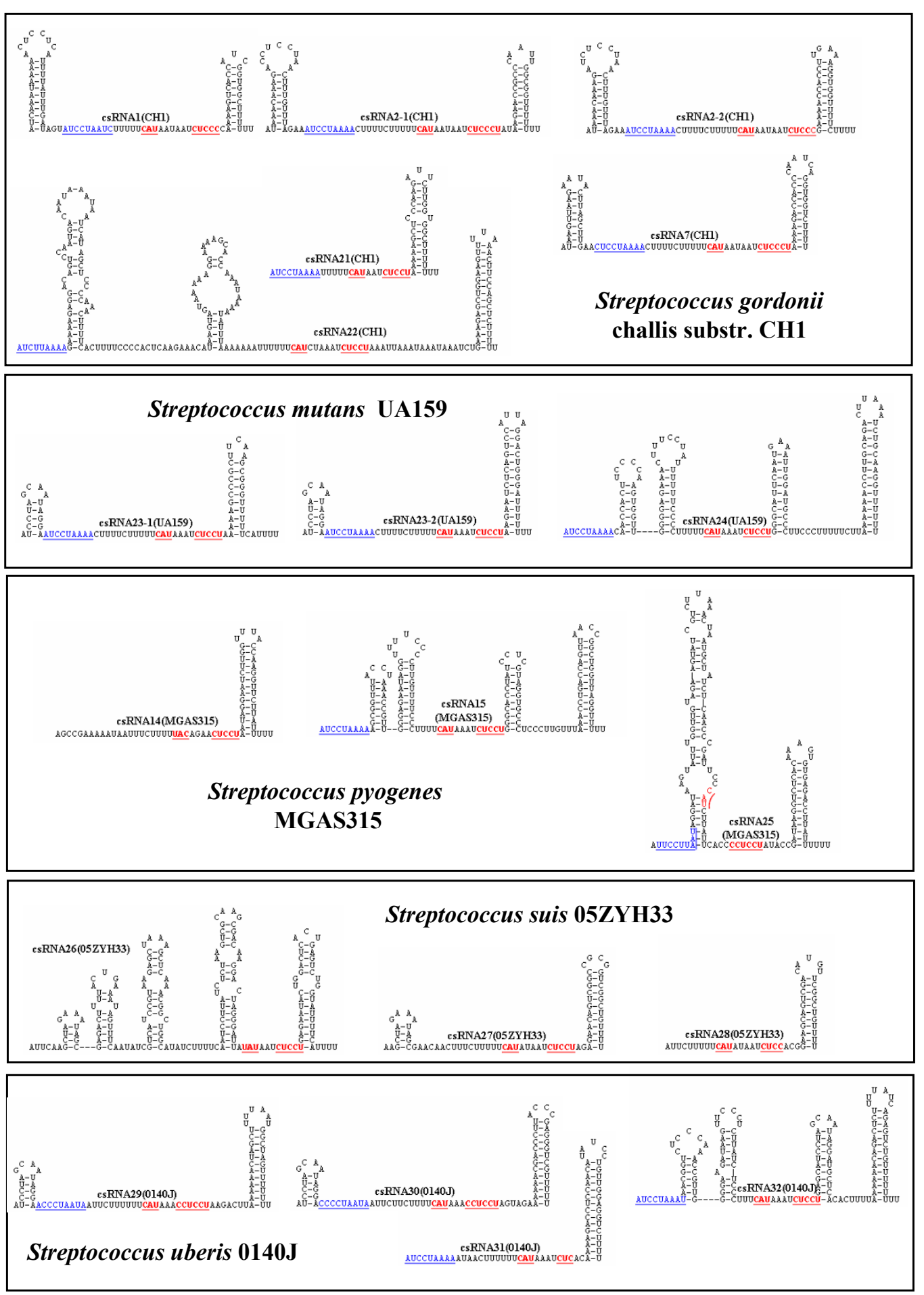

Figure 3 Secondary structures of csRNAs from S. gordonii challis substr. CH1, S. mutans UA159, S. pyogenes MGAS315, S. suis 05ZYH33, and S. uberis 0140J. The csRNA gene predictions from Table 2 were folded using the Mfold program [54]. Sequences

complementary to Shine-Dalgarno [16] sequences or translation initiation codons are underlined and shown in red. A conserved stretch of nucleotides found in virtually all csRNAs is underlined and shown in blue. 

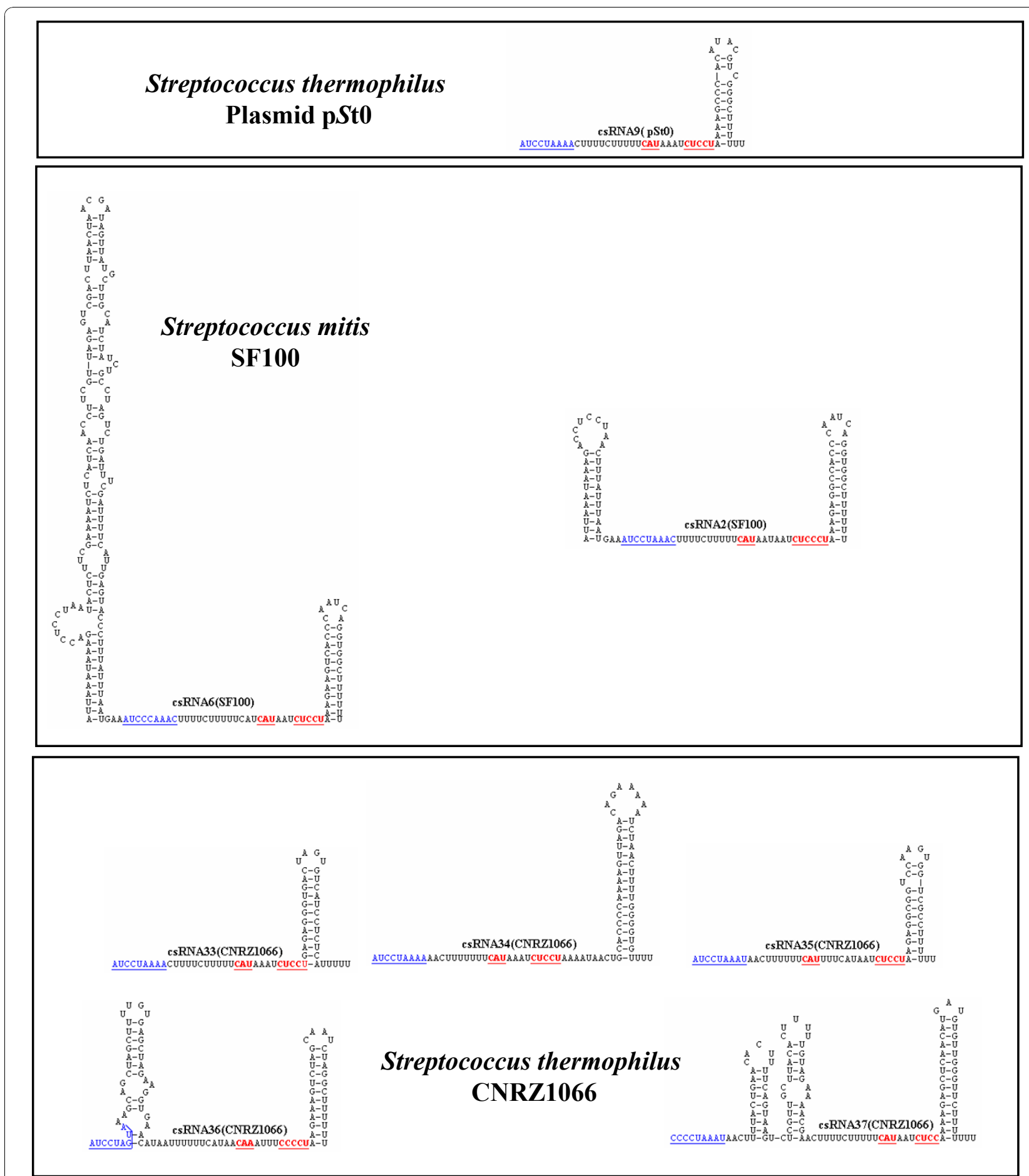

Figure 4 Secondary structures of csRNAs from S. thermophilus plasmid pSt0, S. thermophilus CNRZ1066, and S. mitis SF100. The csRNA gene predictions from Table 2 were folded using the Mfold program [54]. Sequences complementary to Shine-Dalgarno [16] sequences or translation initiation codons are underlined and shown in red. A conserved stretch of nucleotides found in virtually all csRNAs is underlined and shown in blue. S. thermophilus csRNA are not expressed in their native hosts due to ciaR inactivation. 


\section{S. pneumoniae $\mathbf{R 6}$}
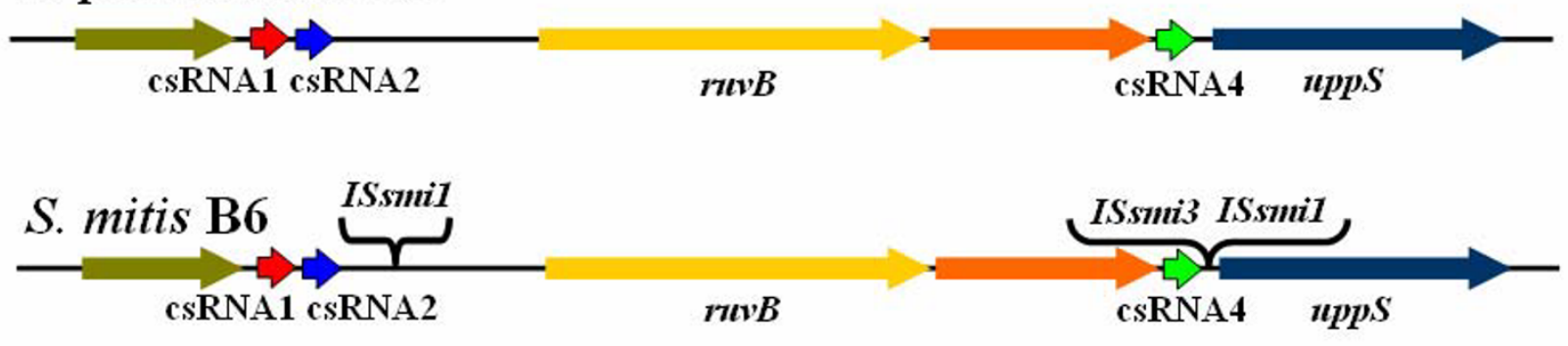

\section{S. oralis $\mathbf{U} \mathbf{0 5}$}

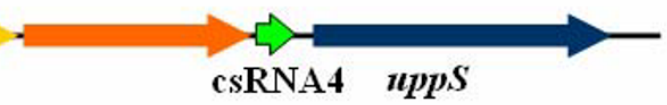

\section{S. sanguinis SK36}

\section{S. gordonii str. Challis substr. CH1}

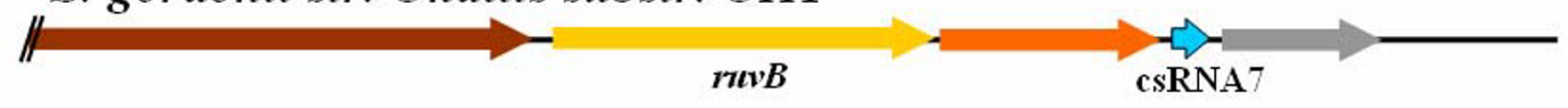

\section{S. gallolyticus UCN34}

$n w \boldsymbol{B}$

\section{S. suis 05ZYH33}

\section{cSRNA26 nivB}

\section{S. uberis 0140J}

\section{nuvB}

\section{csRNA31}

Figure 5 Genomic locations of csRNAs in diverse streptococcal species. The ruvB- uppS region of S. pneumoniae harboring genes for csRNA1, csRNA2, and csRNA4 is compared with the corresponding ruvB-containing loci from S. mitis, S. oralis, S. sanguinis, S. gordonii, S. gallolyticus, S. suis, and S. uberis. Genes with high identity are shown in the same color.

Since $S$. oralis is readily transformable, a ciaR mutant strain was created by integrating a resistance marker into the gene. Subsequently, northern blot analysis was performed to examine csRNA expression in the ciaR mutant strain. Using probes for all S. oralis csRNAs, no signal was detectable in the CiaR-deficient mutant (Figure 6E). This result clearly demonstrates the dependence of csRNA expression on a functional CiaR response regulator.

\section{Expression of a csRNA gene from plasmid pSTO}

S. thermophilus appears to be unique among streptococci, since its CiaRH system is inactivated by mutations. 
The ciaRH genes in the three sequenced S. thermophilus strains CNRZ1066, LMG18311, and LMD9 harbor three identical mutations. Interestingly, a plasmid of another $S$. thermophilus strain ST0 contained a csRNA gene on a plasmid designated pST0 [41] Since this gene was the only one of the predicted csRNA genes that is not located in the genome and the small RNA represented a new type with only one stem-loop structure (csRNA9; Figure 4), we wanted to test its expression. To determine the status of the CiaRH system in that strain, the ciaRH region of $S$. thermophilus ST0 was amplified and sequenced. The same three mutations known from $S$. thermophilus whole genome sequences inactivating both cia genes were detected. Accordingly, using a csRNA9specific probe did not reveal a signal on northern blots using RNA purified from $S$. thermophilus ST0 (data not shown). To provide a functional CiaRH system for csRNA9 expression, the gene, designated $c c n I$, was amplified from plasmid pST0 and cloned into the S. pneumoniae integration vector pMRT2-2 [42] as described in the Methods section. The resulting plasmid pMRT-ccnI was transferred to the S. pneumoniae strain RK12345 expressing no csRNAs [15]. Integration of $c c n I$ occurred in the $b g a A$ locus by double cross-over. RNA purified from that strain (RK12345; bgaA::ccnI) was subjected to northern blot analysis using a csRNA9-specific probe. As shown in Figure 6D, a band smaller than $70 \mathrm{nt}$ was detected corresponding to the csRNA9 of $60 \mathrm{bp}$. Thus, $c c n I$ is indeed expressed when a functional CiaRH system is provided. Consequently, introduction of $c c n I$ into a CiaR-deficient strain (ciaR::aad9) did not result in csRNA9 production (data not shown). It is curious that although the CiaRH system is inactive in S. thermophilus, targets such as csRNA genes have still all necessary expression signals.

\section{Discussion}

By searching data base entries with the consensus sequence for CiaR-activated promoters, 61 genes for csRNAs were predicted in 14 streptococcal species. 17 of these predictions were verified by visualizing csRNAs from $S$. mitis B6, S oralis Uo5, S. sanguinis SK36, and S. thermophilus plasmid pST0 on northern blots. In addition, a recent genome-wide analysis of sRNAs in S. pyogenes [14] identified two sRNAs in strain MGAS2221, which are in fact controlled by CiaR. These sRNAs, SR195750 and SR1719800, correspond to our predicted csRNA15(MGAS315) and csRNA25(MAGAS315), respectively. Their experimentally determined transcriptional start points match exactly the predicted ones for csRNA15 and csRNA25. Since the gene for csRNA14 (MGAS315) is missing in MGAS2221, csRNA14 could not be detected in the study by Perez et al. [14]. The small RNA search in S. pyogenes and our work identified almost one third of the predicted csRNAs strongly suggesting that small RNAs controlled by the response regulator CiaR exist in all streptococci.

Both csRNAs in S. pyogenes are expressed in standard medium during exponential growth and are also detected in stationary phase. The same expression pattern was observed in S. pneumoniae [15] as well as in $S$. mitis, S. oralis and $S$. sanguinis, the streptococcal species used in our study (data not shown). It will be interesting to see if csRNAs will be expressed under similar conditions in all streptococci.

Together with the five csRNAs originally detected in S. pneumoniae, 24 csRNAs have been verified so far by northern blot analysis. Their promoters were therefore used to derive a new consensus sequence for strongly CiaR-activated promoters on a broader basis. To do so, a sequence logo was created by analyzing a multiple promoter sequence alignment by Weblogo [43]. As shown in Figure 7, the repeat sequence TTTAAG is clearly visible, especially in the second part of the repeat. Only the first $\mathrm{T}$ is variable, replaced only twice by $\mathrm{A}$ and $\mathrm{C}$, respectively. The first $\mathrm{T}$ in the first repeat is far less conserved being present in only 11 promoters. In addition, the second $\mathrm{T}$ and the first $\mathrm{A}$ are slightly variable. In both repeats, the third $\mathrm{T}$, the second $\mathrm{A}$ and the final $\mathrm{G}$ are invariable. Thus, the CiaR repeat consensus appears to be NTTAAG-N5-TTTAAG rather than TTTAAG-N5-TTTAAG as proposed earlier [15]. Besides the conservation of the -10 region there is a $\mathrm{C}$ preferentially found immediately upstream of the transcription initiation site. The significance of this observation is not clear at the moment.

The majority of sRNAs characterized to date exert their regulatory function by base pairing to mRNAs [1]. These sRNAs regulate translation and/or stability of target mRNAs, in most cases negatively. Quite often, access to the ribosome binding site is blocked by sRNA-mRNA base pairing. The csRNAs of $S$. pneumoniae and those characterized or predicted in this work show complementarity to translation initiation regions (TIR). They can potentially base pair with the ShineDalgarno (SD) sequence [16] including the following start codon (Figures 1, 2, 3 and 4). These anti-SD and anti-start codon sequences are located in unpaired regions of the csRNAs (Figures 1, 2, 3 and 4). In 53 of the 61 csRNAs, CAU is found potentially serving as an anti-AUG. In the remaining nine csRNAs, anti-GUG and anti-UUG sequences are present. The anti-TIR sequences in all csRNAs strongly suggest that these sRNAs bind to mRNAs to hinder access of ribosomes thereby blocking translation initiation. It will be interesting to determine and compare their molecular targets in diverse streptococcal species.

Although the potentiality to target TIRs of mRNAs is a common feature of the csRNAs, primary sequence 


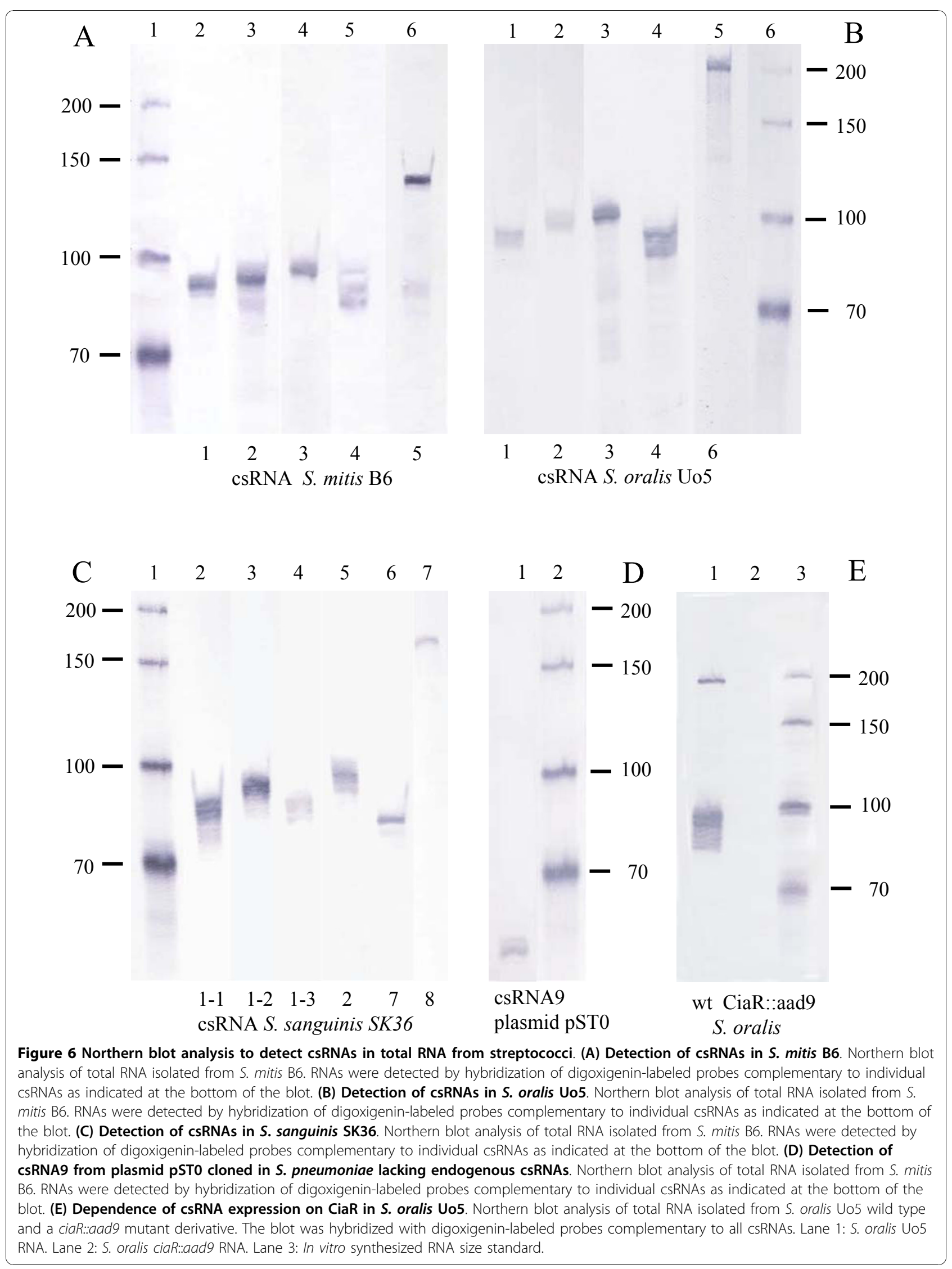




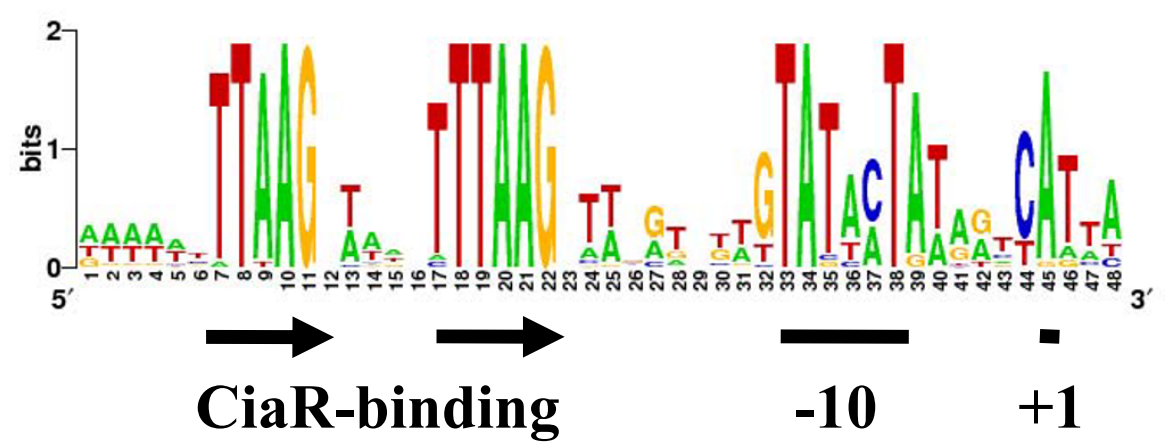

Figure 7 Sequence logo of streptococcal promoters for csRNA genes shown to be expressed by northern blots. The logo was produced by WebLogo [43] using a multiple alignment of promoter sequences of csRNA genes from S. pneumoniae R6, S. mitis B6, S. oralis Uo5, S. pyogenes MGAS2221, and plasmid pST0.

conservation within the anti-TIR regions is rather limited. In addition, overall similarity of the csRNAs is poor. However, a short stretch of conserved nucleotides is found in almost all csRNAs (Figures 1, 2, 3 and 4). Sequences very similar to $[\mathrm{A} / \mathrm{C}] \mathrm{UCCUAAA}[\mathrm{A} / \mathrm{C}]$ originally defined for the csRNAs of closely related S. pneumoniae [15], S. mitis, and S. oralis are present in all but four csRNAs (Figures 1, 2, 3 and 4). Comparing all sequences indicated that the last position in this nonamer is less conserved than anticipated from the S. pneumoniae, S. mitis, and S. oralis comparison. The nonamer is located immediately downstream of the first stemloop or at the 5'-end of the csRNAs (Figures 1, 2, 3 and 4). It is missing in csRNA14 and, curiously, in all csRNAs predicted in S. suis.

If blocking ribosome binding sites by anti-TIR sequences would be the primary mode of action of the csRNAs, the conserved sequence introduced above should have another function. A protein binding site would be an attractive hypothesis. The global post-transcriptional regulator $\mathrm{Hfq}$ is a key factor in sRNA-mRNA interaction and regulation especially in $E$. coli but also in quite a number of other bacteria [44,45]. In AT-rich Gram-positive bacteria however, a role of Hfq in sRNA-mediated regulatory events is less obvious $[46,47]$ and was only recently demonstrated for the first time with one sRNA in Listeria monocytogenes [48]. In addition, the $h f q$ gene is apparently lacking in enterococci, lactococci, lactobacilli, and streptococci [45]. Assuming that other protein(s) could substitute for Hfq in streptococci, the short conserved sequence in csRNAs may be part of a binding site for this factor.

\section{Conclusions}

Here we have demonstrated that small RNAs predicted on the basis of a CiaR binding site and an appropriately spaced -10 region, which is followed by a transcriptional terminator, are expressed in S. mitis, S. oralis, S. sanguinis and from plasmid pST0. These data, together with published proof of expression of these sRNAs in S. pneumoniae and S. pyogenes, strongly suggest that genes for sRNAs belong to the regulon of the response regulator $\mathrm{CiaR}$ in all streptococcal species. Expression of the CiaR-dependent csRNAs and the associated posttranscriptional regulatory events may be the reason for the pleiotropic phenotypes caused by CiaR-dependent control. Elucidation of the molecular mechanisms of csRNA regulation appears to be crucial to understand the role of CiaR in streptococcal physiology. Hence, the suggestion of S. Gottesman to 'watch for small RNAs in all your favourite regulatory circuits' [49] is especially rewarding for the CiaR regulon in streptococci.

\section{Methods}

\section{Prediction of csRNA genes}

To detect csRNA genes in organisms other than $S$. pneumoniae, BLAST [39] searches were performed using the nucleotide collection (nt/nr) database at NCBI. Only very few full-length hits were obtained, but quite a number of short stretches of similarity was detected. Thus, simply looking for similarity did not appear to be adequate to identify csRNA genes.

We therefore applied a more specific search using the known structure of CiaR-activated promoters in combination with transcriptional terminators. The promoters were predicted with Motif search and terminators were identified with TransTermHP. Both programs are combined in a service designated the Non-coding RNA Gene Finder available at [50]. Motif search is also separately available at [51]. It uses Rnabob to find motifs in genomic DNA. Rnabob is a program freely available from [52]. The transcriptional terminator prediction program has been described [53]

The RNA gene finder first finds user defined patterns and subsequently searches for transcriptional terminators in a user defined distance. The candidate RNA is then folded by means of Mfold [54]. 
The csRNAs listed in Table 2 were predicted using TTTAAG for the first two parts of motif search allowing one mismatch each. The distance between the two TTTAAG stretches was set to five. The third part represented the -10 region TATAAT. Two mismatches were allowed and the distance to the last TTTAAG was ten. The terminator structure was searched in a distance of 250 to the -10 region. Results obtained in this way were inspected and hits showing a mismatch at the $G$ positions within TTTAAG were discarded, since it has been shown, that this residue is extremely important for efficient CiaR-mediated gene activation [15]. The predicted csRNAs were folded using Mfold [54] allowing no widerange interactions that are more than 50 nucleotides apart. The results of these secondary structure predictions are shown in Figures 1, 2, 3 and 4. For nearly all csRNAs exceeding 100 bases in length, more than one structure was predicted. In these cases, the most stable structure is shown. The corresponding promoter sequences are listed in the additional file 1.

The DNAs that were searched included streptococcal whole genome sequences listed in Table 1 and those GenBank entries that yielded short BLAST hits with csRNA sequences from $S$. pneumoniae. With the csRNA genes detected in this way, BLAST searches were again performed, but yielded no further csRNA candidates. It appears, however, that incomplete remnants of csRNAs are present in some data base entries.

\section{Bacterial strains and growth conditions}

The streptococcal species S. mitis B6 [55], S. oralis Uo5 [56] and S. sanguinis SK36 [57] were used for RNA isolation to detect csRNAs. From $S$. thermophilus ST0 [41], plasmid pST0 was purified. S. pneumoniae RK12345 [15], a derivative of S. pneumoniae R6 [58] devoid of all five csRNAs served for integrational cloning of $c c n I$ from plasmid pST0. RCR1, a ciaR mutant of S. pneumoniae R6 was used to confirm the CiaR dependency of $c c n I$ expression. Escherichia coli DH5 $\alpha$ [Ф80 dlacZ $\Delta \mathrm{M} 15 \Delta$ (lacZYAargF) recA1 endA1 hsdR17 supE44 thi-1 gyrA96 phoA relA1] was used for cloning procedures.

Streptococci were grown at $37^{\circ} \mathrm{C}$ without aeration; $S$. mitis, S. oralis, and S. pneumoniae in C+Y medium [59] $S$. sanguinis in Brain Heart Infusion broth, and $S$. thermophilus in LM17 medium (0.5\% Lactose). E. coli was grown aerobically in LB-medium.

\section{Integration of $\mathrm{ccnl}$ into the genome of S. pneumoniae}

Since $S$. thermophilus is a natural ciaRH mutant, the gene $c c n I$, specifying csRNA9 and located on S. thermophilus pST0, should be expressed in S. pneumoniae. For that purpose, the integrative vector pMRT2-2 was applied, which is the ancestor of the reporter plasmids pTP1 and pPP2 without E. coli lac $Z[42,60]$. The region of the putative csRNA gene ccnI present on pST0 was amplified by a PCR Primer pair containing BamHI and SphI sites, respectively (cgcggatccGCAGACAATAGCACTCGTATAGATG; ggcgcatgcCATTTATCCGTG CGTCATCG). PCR amplification and cloning in E. coli was carried out by standard procedures as described [15]. The resulting plasmid pMRT2-2-ccnI was introduced into S. pneumoniae RK12345 as described [15]. After transformation of RK12345 with pMRT2-2-ccnI, correct integration of $c c n I$ into the $b g a A$ locus in the $S$. pneumoniae genome was confirmed by PCR and DNA sequencing. The ccnI-containing plasmid was also used to transform RCR1, a ciaR mutant of S. pneumoniae R6. RNA from both strains with integrated $c c n I$ was isolated and subjected to northern blot analysis.

\section{RNA purification and northern blot analysis}

The strains were grown in the media mentioned above to an $\mathrm{OD}_{600}$ of 0.8 corresponding to late logarithmic growth phase. RNA purification and northern blot analysis was carried out as described previously [15] Synthetic oligonucleotides specific for individual csRNAs were labeled with digoxigenin-ddUTP and terminal transferase as described in the DIG Oligonucleotide 3'-end labeling kit instructions (Roche). Oligonucleotides used for csRNA detection are listed in the additional file 2. The following nucleotide, CCACTAGTTCTAGAGCCGGCCGCCACCGCGGTGGAGCTCCAATTCGCCC, was applied to visualize the RNA size standard prepared as described [15].

\section{Construction of a ciaR mutant strain of S. oralis Uo5}

To inactivate the ciaR gene in S. oralis Uo5, the ciaR:: aad9 region from $S$. pneumoniae RCR1 was amplified by primers located $1 \mathrm{~kb}$ up-and downstream of the aad 9 insertion site. Due to the high similarity of the ciaRH region in S. pneumoniae and S. oralis Uo5 (around 90\% identity) it was expected that the $S$. pneumoniae DNA should be integratable into $S$. oralis. Competent $S$. oralis cells were obtained according to the $S$. pneumoniae procedure and selection with $80 \mu \mathrm{g} / \mathrm{ml}$ spectinomycin readily yielded transformants with disrupted ciaR.

\section{Additional material}

Additional file 1: Alignment of csRNA promoters from streptococci. All predicted CiaR-dependent promoters driving expression of small noncoding csRNAs are shown.

Additional file 2: Oligonucleotides used to detect csRNAs

Oligonucleotides used as probes to detect csRNAs are listed.

\section{Acknowledgements}

We are grateful to A. Geis for kindly providing S. thermophilus STO and pSTO plasmid DNA. The work presented here was sponsored in part by a Grant to R.B. within the priority program "Sensory and regulatory RNAs in 
Prokaryotes" of the German Research Foundation (BR947-5/1) and the Stiftung Rheinland Pfalz für Innovation to R. H. (15202 - 3862 61/580).

\section{Author details}

'Department of Microbiology, University of Kaiserslautern, D-67663 Kaiserslautern, Germany. ${ }^{2}$ European Bioinformatics Institute, Wellcome Trust Genome Campus, Hinxton, Cambridge CB10 1SD, UK

\section{Authors' contributions}

PM and MK performed the experiments. $\mathrm{RH}$ provided strains and genome sequences. MN performed bioinformatic analyses. RB designed research and wrote the manuscript. All authors read and approved the final manuscript.

Received: 16 July 2010 Accepted: 24 November 2010

Published: 24 November 2010

\section{References}

1. Waters LS, Storz G: Regulatory RNAs in bacteria. Cell 2009, 136:615-628.

2. Altuvia S: Identification of bacterial small non-coding RNAs: experimental approaches. Curr Opin Microbiol 2007, 10:257-261.

3. Livny J, Waldor MK: Identification of small RNAs in diverse bacterial species. Curr Opin Microbiol 2007, 10:96-101.

4. Sharma CM, Vogel J: Experimental approaches for the discovery and characterization of regulatory small RNA. Curr Opin Microbiol 2009.

5. Liu JM, Livny J, Lawrence MS, Kimball MD, Waldor MK, Camilli A: Experimental discovery of sRNAs in Vibrio cholerae by direct cloning, 5S/ tRNA depletion and parallel sequencing. Nucleic Acids Res 2009, 37:e46.

6. Mandin P, Repoila F, Vergassola M, Geissmann T, Cossart P: Identification of new noncoding RNAs in Listeria monocytogenes and prediction of mRNA targets. Nucleic Acids Res 2007, 35:962-974.

7. Pichon C, Felden B: Small RNA genes expressed from Staphylococcus aureus genomic and pathogenicity islands with specific expression among pathogenic strains. Proc Natl Acad Sci USA 2005, 102:14249-11454.

8. Rasmussen $\mathrm{S}$, Nielsen $\mathrm{HB}$, Jarmer $\mathrm{H}$ : The transcriptionally active regions in the genome of Bacillus subtilis. Mol Microbiol 2009, 73:1043-1057.

9. Toledo-Arana A, Dussurget O, Nikitas G, Sesto N, Guet-Revillet H, Balestrino D, Loh E, Gripenland J, Tiensuu T, Vaitkevicius K, et al: The Listeria transcriptional landscape from saprophytism to virulence. Nature 2009, 459:950-956

10. Irnov I, Sharma CM, Vogel J, Winkler WC: Identification of regulatory RNAs in Bacillus subtilis. Nucleic Acids Res 2010.

11. Kreikemeyer B, Boyle MD, Buttaro BA, Heinemann M, Podbielski A: Group A streptococcal growth phase-associated virulence factor regulation by a novel operon (Fas) with homologies to two-component-type regulators requires a small RNA molecule. Mol Microbiol 2001, 39:392-406.

12. Mangold M, Siller M, Roppenser B, Vlaminckx BJ, Penfound TA, Klein R, Novak R, Novick RP, Charpentier E: Synthesis of group A streptococcal virulence factors is controlled by a regulatory RNA molecule. $\mathrm{Mol}$ Microbiol 2004, 53:1515-1527.

13. Roberts SA, Scott JR: RivR and the small RNA RivX: the missing links between the CovR regulatory cascade and the Mga regulon. $\mathrm{Mol}$ Microbiol 2007, 66:1506-1522.

14. Perez N, Trevino J, Liu Z, Ho SC, Babitzke P, Sumby P: A genome-wide analysis of small regulatory RNAs in the human pathogen group $A$ Streptococcus. PLoS One 2009, 4:e7668.

15. Halfmann A, Kovacs M, Hakenbeck R, Brückner R: Identification of the genes directly controlled by the response regulator CiaR in Streptococcus pneumoniae: five out of 15 promoters drive expression of small non-coding RNAs. Mol Microbiol 2007, 66:110-126.

16. Shine J, Dalgarno L: The 3 '-terminal sequence of Escherichia coli $16 \mathrm{~S}$ ribosomal RNA: complementarity to nonsense triplets and ribosome binding sites. Proc Natl Acad Sci USA 1974, 71:1342-1346.

17. Tsui H-CT, Mukherjee D, Ray VA, Sham LT, Feig AL, Winkler ME: Identification and Characterization of Non-Coding Small RNAs in Streptococcus pneumoniae Serotype 2 Strain D39. J Bacteriol 2009, 192:264-279.

18. Kumar R, Shah P, Swiatlo E, Burgess S, Lawrence M, Nanduri B: Identification of novel non-coding small RNAs from Streptococcus pneumoniae TIGR4 using high-resolution genome tiling arrays. 2010, 11:350.
19. Guenzi E, Gasc AM, Sicard MA, Hakenbeck R: A two-component signaltransducing system is involved in competence and penicillin susceptibility in laboratory mutants of Streptococcus pneumoniae. Mol Microbiol 1994, 12:505-515.

20. Dagkessamanskaia A, Moscoso M, Henard V, Guiral S, Overweg K, Reuter M, Martin B, Wells J, Claverys JP: Interconnection of competence, stress and CiaR regulons in Streptococcus pneumoniae: competence triggers stationary phase autolysis of ciaR mutant cells. Mol Microbiol 2004, 51:1071-1086

21. Ibrahim YM, Kerr AR, McCluskey J, Mitchell TJ: Control of virulence by the two-component system $\mathrm{CiaR} / \mathrm{H}$ is mediated via $\mathrm{HtrA}$, a major virulence factor of Streptococcus pneumoniae. J Bacteriol 2004, 186:5258-5266.

22. Mascher T, Heintz M, Zähner D, Merai M, Hakenbeck R: The CiaRH system of Streptococcus pneumoniae prevents lysis during stress induced by treatment with cell wall inhibitors and mutations in pbp2x involved in beta-lactam resistance. J Bacteriol 2006, 188:1959-1978.

23. Mascher T, Zähner D, Merai M, Balmelle N, de Saizieu AB, Hakenbeck R: The Streptococcus pneumoniae cia regulon: CiaR target sites and transcription profile analysis. J Bacteriol 2003, 185:60-70.

24. Sebert ME, Patel KP, Plotnick M, Weiser JN: Pneumococcal HtrA protease mediates inhibition of competence by the CiaRH two-component signaling system. J Bacteriol 2005, 187:3969-3979.

25. Dawid S, Sebert ME, Weiser JN: Bacteriocin activity of Streptococcus pneumoniae is controlled by the serine protease HtrA via posttranscriptional regulation. J Bacteriol 2009, 191:1509-1518.

26. Ahn SJ, Lemos JAC, Burne RA: Role of HtrA in Growth and Competence of Streptococcus mutans UA159. 2005, 187:3028-3038.

27. Biswas I, Drake L, Erkina D, Biswas S: Involvement of sensor kinases in the stress tolerance response of Streptococcus mutans. J Bacteriol 2008, 190:68-77.

28. Lévesque CM, Mair RW, Perry JA, Lau PC, Li YH, Cvitkovitch DG: Systemic inactivation and phenotypic characterization of two-component systems in expression of Streptococcus mutans virulence properties. Lett Appl Microbiol 2007, 45:398-404.

29. Qi F, Merritt J, Lux R, Shi W: Inactivation of the ciaH Gene in Streptococcus mutans diminishes mutacin production and competence development, alters sucrose-dependent biofilm formation, and reduces stress tolerance. Infect Immun 2004, 72:4895-4899.

30. Liu Y, Burne RA: Multiple Two-Component Systems of Streptococcus mutans Regulate Agmatine Deiminase Gene Expression and Stress Tolerance. J Bacteriol 2009, 191:7363-7366.

31. Liu Y, Burne RA: Multiple Two-Component Systems Modulate Alkali Generation in Streptococcus gordonii in Response to Environmental Stresses. J Bacteriol 2009, 191:7353-7362.

32. Quach D, van Sorge NM, Kristian SA, Bryan JD, Shelver DW, Doran KS: The CiaR response regulator in group B Streptococcus promotes intracellular survival and resistance to innate immune defenses. J Bacteriol 2009, 191:2023-2032.

33. Riani C, Standar K, Srimuang S, Lembke C, Kreikemeyer B, Podbielski A: Transcriptome analyses extend understanding of Streptococcus pyogenes regulatory mechanisms and behavior toward immunomodulatory substances. Int J Med Microbiol 2007, 297:513-523.

34. Wu C, Ayala EA, Downey JS, Merritt J, Goodman SD, Qi F: Regulation of ciaXRH operon expression and identification of the $\mathrm{CiaR}$ regulon in Streptococcus mutans. J Bacteriol 2010, 192:4669-4679.

35. Jordan S, Hutchings MI, Mascher T: Cell envelope stress response in Gram-positive bacteria. FEMS Microbiol Rev 2008, 32:107-146.

36. Martínez-Hackert E, Stock AM: Structural relationships in the OmpR family of winged-helix transcription factors. J Mol Biol 1997, 269:301-312.

37. Martínez-Hackert E, Stock AM: The DNA-binding domain of OmpR: crystal structures of a winged helix transcription factor. Structure 1997, 5:109-124.

38. Bolotin A, Quinquis B, Renault P, Sorokin A, Ehrlich SD, Kulakauskas S, Lapidus A, Goltsman E, Mazur M, Pusch GD, et al: Complete sequence and comparative genome analysis of the dairy bacterium Streptococcus thermophilus. Nat Biotechnol 2004, 22:1554-1558.

39. Altschul SF, Gish W, Miller W, Myers EW, Lipman DJ: Basic local alignment search tool. J Mol Biol 1990, 215:403-410.

40. Bensing BA, Rubens CE, Sullam PM: Genetic Loci of Streptococcus mitis That Mediate Binding to Human Platelets. Infect Immun 2001, 69:1373-1380. 
41. Geis A, El Demerdash HA, Heller KJ: Sequence analysis and characterization of plasmids from Streptococcus thermophilus. Plasmid 2003, 50:53-69.

42. Kovács M, Halfmann A, Fedtke I, Heintz M, Peschel A, Vollmer W, Hakenbeck R, Brückner R: A Functional dlt Operon, encoding proteins required for incorporation of $D$-alanine in teichoic acids in gram-positive bacteria, confers resistance to cationic antimicrobial peptides in Streptococcus pneumoniae. J Bacteriol 2006, 188:5797-5805.

43. Crooks GE, Hon G, Chandonia JM, Brenner SE: WebLogo: a sequence logo generator. Genome Res 2004, 14:1188-1190.

44. Chao Y, Vogel J: The role of Hfq in bacterial pathogens. Curr Opin Microbiol 2010, 13:24-33.

45. Valentin-Hansen P, Eriksen M, Udesen C: The bacterial Sm-like protein Hfq: a key player in RNA transactions. Mol Microbiol 2004, 51:1525-1533.

46. Bohn C, Rigoulay C, Bouloc P: No detectable effect of RNA-binding protein Hfq absence in Staphylococcus aureus. BMC Microbiol 2007, 7:10.

47. Jousselin $A$, Metzinger $L$, Felden $B$ : On the facultative requirement of the bacterial RNA chaperone, Hfq. Trends Microbiol 2009, 17:399-405.

48. Nielsen JS, Lei LK, Ebersbach T, Olsen AS, Klitgaard JK, Valentin-Hansen P, Kallipolitis BH: Defining a role for Hfq in Gram-positive bacteria: evidence for Hfq-dependent antisense regulation in Listeria monocytogenes. Nucleic Acids Res 2010, 38:907-919.

49. Gottesman S: Small RNAs shed some light. Cell 2004, 118:1-2.

50. Nuhn M: Non coding RNA gene finder. [http://nbc11.biologie.uni-kl.de/ ncRnaGeneFinder/index.pl].

51. Nuhn M: Motif search. [http://nbc11.biologie.uni-kl.de/motifsearch2/index $\mathrm{pl}$.

52. Eddy : Eddy Lab: Software. [http://selab.janelia.org/software.html].

53. Kingsford CL, Ayanbule K, Salzberg SL: Rapid, accurate, computational discovery of Rho-independent transcription terminators illuminates their relationship to DNA uptake. Genome Biol 2007, 8:R22.

54. Zuker M: Mfold web server for nucleic acid folding and hybridization prediction. Nucleic Acids Res 2003, 31:3406-3415.

55. Denapaite D, Brückner R, Nuhn M, Reichmann P, Henrich B, Maurer P, Schähle Y, Selbmann P, Zimmermann W, Wambutt R, Hakenbeck R: The genome of Streptococcus mitis B6-what is a commensal? PLoS One 2010, 5:e9426.

56. Reichmann P, König A, Linares J, Alcaide F, Tenover FC, McDougal L, Swidsinski S, Hakenbeck R: A global gene pool for high-level cephalosporin resistance in commensal Streptococcus species and Streptococcus pneumoniae.. J Infect Dis 1997, 176:1001-1012.

57. Xu P, Alves JM, Kitten T, Brown A, Chen Z, Ozaki LS, Manque P, Ge X, Serrano MG, Puiu D, et al: Genome of the Opportunistic Pathogen Streptococcus sanguinis. J Bacteriol 2007, 189:3166-3175.

58. Ottolenghi $E$, Hotchkiss RD: Release of genetic transforming agent from pneumococcal cultures during growth and disintegration. J Exp Med 1962, 116:491-519

59. Ottolenghi E, Hotchkiss RD: Appearance of genetic transforming activity in pneumococcal cultures. Science 1960, 132:1257-1258.

60. Halfmann A, Hakenbeck R, Brückner R: A new integrative reporter plasmid for Streptococcus pneumoniae. FEMS Microbiol Lett 2007, 268:217-224.

doi:10.1186/1471-2164-11-661

Cite this article as: Marx et al:: Identification of genes for small noncoding RNAs that belong to the regulon of the two-component regulatory system CiaRH in Streptococcus. BMC Genomics 2010 11:661.

\section{Submit your next manuscript to BioMed Central and take full advantage of:}

- Convenient online submission

- Thorough peer review

- No space constraints or color figure charges

- Immediate publication on acceptance

- Inclusion in PubMed, CAS, Scopus and Google Scholar

- Research which is freely available for redistribution

Submit your manuscript at www.biomedcentral.com/submit
Biomed Central 